BMJ Open

Diabetes

Research

\& Care

\title{
Assessment of diabetes and prediabetes prevalence and predictors by HbA1c in a population from sub-Saharan Africa with a high proportion of anemia: a prospective cross-sectional study
}

\author{
Nikolai Carl Hodel, ${ }^{1,2}$ Ali Hamad, ${ }^{3}$ Klaus Reither, ${ }^{2,3}$ Grace Mwangoka, ${ }^{3}$ \\ Irene Kasella, ${ }^{4}$ Claudia Praehauser, ${ }^{1}$ Salim Abdulla, ${ }^{3}$ Christoph F R Hatz, ${ }^{2,5}$ \\ Michael Mayr (1) ${ }^{1}$
}

To cite: Hodel NC, Hamad A, Reither $\mathrm{K}$, et al. Assessment of diabetes and prediabetes prevalence and predictors by HbA1c in a population from sub-Saharan Africa with a high proportion of anemia: a prospective cross-sectional study. BMJ Open Diab Res Care 2020;8:e000939. doi:10.1136/ bmjdrc-2019-000939

\section{- Additional material is published online only. To view please visit the journal online (http://dx.doi.org/10.1136/ bmjdrc-2019-000939).}

Received 27 September 2019 Revised 18 March 2020 Accepted 24 March 2020

Check for updates

C Author(s) (or their employer(s)) 2020. Re-use permitted under CC BY-NC. No commercial re-use. See rights and permissions. Published by BMJ.

For numbered affiliations see end of article.

Correspondence to Dr Michael Mayr; Michael.mayr@usb.ch

\section{ABSTRACT}

Introduction Epidemiological data about diabetes mellitus (DM) for sub-Saharan Africa (SSA) are scarce and the utility of glycated hemoglobin $(\mathrm{HbA1c})$ to diagnose $\mathrm{DM}$ is uncertain in African populations with a high proportion of anemia.

Research design and methods In a cross-sectional study, age-adjusted prevalence rates and predictors for DM and pre-DM were prospectively assessed by $\mathrm{HbA1c}$ in a semirural walk-in population of Tanzania $(n=992)$. Predictors for DM were calculated by logistic regression. Correlations between $\mathrm{HbA1c}$, hemoglobin, and blood glucose levels were done by Pearson's correlation.

Results Overall, DM and pre-DM prevalence rates were $6.8 \%$ (95\% Cl 5.3 to 8.5$)$ and $25 \%$ (95\% Cl 22.8 to 28.3$)$, respectively. There was an increase in DM prevalence in patients $50-59$ (14.9\%; $95 \% \mathrm{Cl} 9.1$ to 22.5$)$, $\geq 60$ years old (18.5\%; $95 \% \mathrm{Cl} 12.2$ to 26.2$)$ and in patients with overweight (9.3\%; $95 \% \mathrm{Cl} 5.9$ to 13.7$)$, obesity (10.9\%; $95 \% \mathrm{Cl} 6.9$ to 16) compared with patients $18-29$ years old $(2.2 \% ; 95 \% \mathrm{Cl}$ 0.9 to 4.4$)(p<0.001)$ and to normal-weight patients $(3.6 \%$; $95 \% \mathrm{Cl} 2.1$ to 5.6$)(\mathrm{p}<0.01)$, respectively. Age (OR 1.08, $95 \% \mathrm{Cl} 1.05$ to 1.12; $p<0.001)$, body mass index (BMI) (OR $1.10,95 \% \mathrm{Cl} 1.04$ to $1.16 ; \mathrm{p}<0.001)$, and acute infection (OR 3.46, 95\% Cl 1.02 to 10.8; $p=0.038$ ) were predictors for DM. Comparing patients with a BMl of $20 \mathrm{~kg} / \mathrm{m}^{2}$ and a BMI of $35 \mathrm{~kg} / \mathrm{m}^{2}$, the relative risk for DM increases in average by 2.12-fold (range 1.91-2.24) across the age groups. Comparing patients 20 years old with patients 70 years old, the relative risk for DM increases in average 9.7-fold (range 8.9-10.4) across the BMI groups. Overall, 333 patients (36\%) suffered from anemia. Pearson's correlation coefficients $(r)$ between $\mathrm{HbA1c}$ and hemoglobin was $-0.009(\mathrm{p}=0.779)$, and between $\mathrm{HbA1c}$ and fasting blood glucose and random blood glucose, it was 0.775 and 0.622 , respectively $(p<0.001)$. Conclusion We observed a high prevalence of DM and pre-DM, mainly triggered by increasing age and BMI, and provide evidence that $\mathrm{HbA1c}$ is suitable to assess DM also in populations of SSA with high proportions of anemia. Trial registration number NCT03458338.

\section{BACKGROUND}

For the pastfew decades, diabetes mellitus (DM) and especially type 2 DM became a major global

\section{Significance of this study}

What is already known about this subject?

- Epidemiological data about prevalence rates of diabetes mellitus (DM) and prediabetes for sub-Saharan Africa are scarce and heterogenic.

- The utility of glycated hemoglobin $(\mathrm{HbA1c})$ to diagnose DM is uncertain in African populations with a high proportion of anemia.

- Data about the impact of the pandemic of excess body weight and increasing life expectancy on prevalence rates of diabetes are scarce in regions of sub-Saharan Africa.

What are the new findings?

- High overall prevalence rate of diabetes $(6.8 \%)$ and dramatic high of prediabetes $(25 \%)$ in a subSaharan Africa population.

- The relative risk for DM is nearly 10 -fold higher in 70-year-old than in 20-year-old patients and on average twofold higher in patients with a body mass index (BMI) of $35 \mathrm{~kg} / \mathrm{m}^{2}$ compared with patients with a BMl of $20 \mathrm{~kg} / \mathrm{m}^{2}$

- There is good evidence that $\mathrm{HbA1c}$ testing to diagnose diabetes can also be applied in African populations with large proportion of anemia.

How might these results change the focus of research or clinical practice?

- HbA1c testing could be a useful tool for detecting diabetes and prediabetes to enable early intervention strategies against the diabetes pandemic.

public health problem. ${ }^{12}$ Projections for the increase of DM prevalence are most dramatic for developing countries, ${ }^{1-3}$ and in particular for sub-Saharan Africa (SSA) as consequence of the fast demographic and epidemiological transition. ${ }^{34}$ Therefore, prevention and strategies against DM are on the current agenda of many developing countries including Tanzania 
and other nations in SSA. ${ }^{4}$ However, epidemiological data about DM prevalence are relatively scarce in the region, ${ }^{35}$ and most studies in Tanzania were conducted in the 1980s and 1990s. ${ }^{5-9}$ At that time, the DM prevalence in Tanzania was estimated at about $2 \%$ and impaired glucose tolerance at about $8 \%$, with a trend of a higher prevalence in urban areas than in rural areas. ${ }^{5-9}$ The 2016 WHO diabetes profile estimates a current DM prevalence of $4.3 \%$ in Tanzania and illustrates a clear trend of rising numbers for the past three decades. ${ }^{10}$ However, this might not reflect the true burden of this chronic disorder, because according to the International Diabetes Foundation (IDF) Diabetes Atlas from 2017, an estimated majority (>60\%) of DM remains undiagnosed in SSA. In the light of these trends and projections, approaches for better screening and early diagnosis of DM are most needed. ${ }^{111}$

None of the diagnostic methods for the detection of DM is considered a true "gold standard" test. ${ }^{12}{ }^{13}$ Conventionally, blood glucose levels are determined in either a fasting state or at random, or after the intake of a standard portion of glucose.$^{13}$ In recent years, however, the switch to a glycated hemoglobin (HbAlc) based diabetes diagnosis found more evidence-based support. ${ }^{13-15}$ Although HbAlc tests are expensive compared with blood glucose measurements, ${ }^{15}$ Dagogo-Jack et al pointed out in a recent publication, that HbAlc testing offers "real hope" for research and clinical work in SSA, as the less demanding logistics allow the test application even in remote parts of the continent. ${ }^{15}$

However, the diagnosis of DM based on HbAlc also presents substantial difficulties and needs further exploration. The method is based on the entire lifespan of the erythrocyte, and HbAlc is an intergrated index over this time period with indication of chronic glycemia rather than glycemia at a particular point in time. ${ }^{1316}$ Therefore, HbA1c can be affected by genetics and hematologic factors. ${ }^{14-16}$ The latter aspect may be of particular importance in SSA where a high proportion of the population is affected by anemia. ${ }^{1718}$

The aim of our study was to estimate the prevalence rates and predictors of DM and pre-DM based on HbAlc measurements, in a semirural walk-in population of Tanzania where anemia is highly prevalent.

\section{METHODS}

\section{Study population and setting}

This is a prospective cross-sectional study performed from December 8, 2010 to May 30, 2011. The study population covers a walk-in population of the outpatient clinic (OPC) of the Bagamoyo District Hospital (BDH) as part of the RenalOne study as previously described ${ }^{17}$ Briefly, the BDH is located in Bagamoyo township and provides care for a semirural population. Bagamoyo district had approximately 300000 inhabitants in the 2012 census. $^{19}$ The OPC was visited on average by 120 (range 41-164) patients daily (survey performed from NH from December 1, 2010 to May 31, 2011). For the current study, one consultation hour of the general outpatient ward was designated to ensure a highly standardized procedure. From the newly registered patients of the OPC, 15-20 patients per day were consecutively seen, and the call-up of the patients from the OPC ward was done through the medical staff, without any involvement of the investigators. Pregnant women, patients younger than 18 years, and patients neither able nor willing to provide informed consent were excluded. All participants signed an informed consent form in Swahili. For illiterate patients, the consent form has been read and the fingerprint of the index finger has been used instead of a signature.

\section{Measurements and procedures}

In all participants, medical history of DM and the use of antidiabetic medication were asked. Body weight and height, office blood pressure (BP), heart rate and temperature, and demographic data were recorded. BP was assessed by a single measurement using a manual sphygmomanometer in a sitting position after $5 \mathrm{~min}$ at rest. $\mathrm{HbA1c}$ was measured from capillary blood by using a bed-side DCA 2000+ Analyzer (Siemens Healthcare Diagnostics). Blood glucose was measured from capillary blood using a CONTOUR XT (Bayer Diabetes Care) and time of last meal was recorded. Additionally, a blood sample was taken for complete blood count and serum creatinine. Complete blood count was performed by a Sysmex Xs $800 \mathrm{i}$ analyser. Serum creatinine was measured using Creatinine Jaffe Gen2 reagent on a Cobas Integra 400 plus analyser. Estimated glomerular filtration rate (eGFR) was calculated using the chronic kidney disease epidemiology collaboration (CKD-EPI) formula. ${ }^{20}$ After informed consent, HIVscreening was done with an immunochromatographic test for antibodies to HIV-1 and HIV-2 (test kits: Uni-Gold HIV, Trinity Biotech, Ireland; Determine HIV-1/2, Inverness Medical Japan, Japan; SD BIOLINE HIV-1/2 3.0, SD Standard Diagnostics, Korea). Malaria was diagnosed based on a positive immunochromatographic test (SD BIOLINE Malaria Antigen P.f/Pan, SD Standard Diagnostics, Korea). All participants were instructed to void a clean-urine specimen. Urine samples were prepared for microscopic analysis. Albumin-to-creatinine ratio ${ }^{21}$ was measured using a DCA 2000+ analyser (Siemens Healthcare Diagnostics). All data were collected in a case report form, translated from English to Swahili.

\section{Definitions}

DM was defined if one of the following criteria was fulfilled: a positive history of $\mathrm{DM}$, the use of antidiabetic medication, or a HbAlc of $\geq 6.5 \%(48 \mathrm{mmol} / \mathrm{mol}) .{ }^{22}$ According to the American Diabetes Association (ADA), prediabetes (pre$\mathrm{DM})$ was defined if $\mathrm{HbAlc} \geq 5.7 \%-6.49 \%$ (39-47 mmol/ mol) ${ }^{23}$ Impaired glucose metabolism (IGM) was defined when either a DM or pre-DM was present in a patient. The blood glucose test was considered as fasting blood glucose (FBG) measurement, if the time lag between the last meal and the enrolment time was $\geq 8$ hours. For the correlation with $\mathrm{HbAlc}$ values, a FBG measurement $\geq 7 \mathrm{mmol} / \mathrm{L}$ and a random blood glucose $(\mathrm{RBG}) \geq 11.1 \mathrm{mmol} / \mathrm{L}$ was classified 
as DM, a FBG $\geq 5.6-6.9 \mathrm{mmol} / \mathrm{L}$ and a RBG 7.8-11.1 mmol/L as pre-DM, according to the ADA fasting plasma glucose classification. ${ }^{21}{ }^{24}$ Anemia was defined according to WHO classification, if hemoglobin $(\mathrm{Hb})$ was $<130.0 \mathrm{~g} / \mathrm{L}$ in male and $<120.0 \mathrm{~g} / \mathrm{L}$ in female patients. ${ }^{25}$ Acute systemic infection/inflammation was defined if one of the following criteria was fulfilled: body temperature $\geq 38.5^{\circ} \mathrm{C}$ (armpit), diagnosis of acute malaria, acute tuberculosis, newly diagnosed HIV, and urinary tract infection (UTI). UTI was defined with a cut-off of $>20$ leukocytes/high power field in urinary sediment.

\section{Outcomes}

Primary outcomes of the study were DM, pre-DM, and IGM prevalence rates and predictors based on $\mathrm{HbAlc}$ measurements. Secondary outcome was to explore whether there is a relevant interaction between $\mathrm{HbAlc}$ and $\mathrm{Hb}$ levels.

\section{Statistical analyses}

Statistical analyses were performed using STATA V.14 (Stata, College Station, Texas, USA) and R (V.3.2.3). ${ }^{26}$ Discrete variables were expressed as counts (percentage), and comparison between groups was done with Pearson's $\chi^{2}$ test or Fisher's exact test. Continuous variables were expressed as mean $\pm \mathrm{SD}$ if normally distributed or as median and range if not normally distributed and comparison between groups were done with t-test, Mann-Whitney, or Dunn's test with Holm adjustment as appropriate.

Univariate and multivariate logistic regression was used to determine predictors for DM, pre-DM and IGM. Results were expressed as OR with $95 \%$ confidence intervals (CI). To indicate correlations between $\mathrm{HbAlc}$ and $\mathrm{Hb}$ or blood glucose levels Pearson's correlation tests were performed and the Pearson's correlation coefficient (r) reported. $\mathrm{P}$-values of $<0.05$ were considered as statistically significant.

\section{RESULTS}

The initial study population consisted of 1006 patients. Five patients aged $<18$ years had to be excluded. In nine patients, no HbAlc was measured; therefore, the DM and pre-DM prevalence rates and multivariate analyses for predictors were calculated from $\mathrm{n}=992$ patients. Additionally, in 6 patients age, in three body mass index (BMI), in 19 fasting or RBG levels, and in $72 \mathrm{Hb}$ were missing, leading to $\mathrm{n}=986$, $\mathrm{n}=989, \mathrm{n}=973$, and $\mathrm{n}=920$ available patients for the specific analyses, respectively (online supplementary figure S1).

\section{Patient characteristics}

Patients characteristics are summarized in table 1 . The study population consisted of $301(30 \%)$ males and 691 $(70 \%)$ females. Overall, median HbAlc was $5.4 \%$ (36 $\mathrm{mmol} / \mathrm{mol}$ ) (range $3.9 \%-14.0 \%, 19-130 \mathrm{mmol} / \mathrm{mol}$ ), $\mathrm{HbAlc}<5.7 \%(<39 \mathrm{mmol} / \mathrm{mol})$ was seen in $69 \%(\mathrm{n}=682)$, HbAlc $5.7 \%-6.49 \%(39-47 \mathrm{mmol} / \mathrm{mol})$ in $25 \%(\mathrm{n}=253)$, and $\mathrm{HbAlc} \geq 6.5 \%(\geq 48 \mathrm{mmol} / \mathrm{mol})$ in $6 \%(\mathrm{n}=57)$ of the patients. There was no difference by sex in the proportion of males and females affected by DM, and pre-DM ( $>0.05$ for all). Median age was 36 years (range 18-91 years), and patients with DM (54 years (range 19-91 years)) and pre-DM (44 years (range 18-89 years)) were older than patients without these disorders ((34 (range 18-91 years) and 33 years (range 18-84 years), respectively)) $(\mathrm{p}<0.001)$. BMI was significantly higher in patients with DM $(27 \mathrm{~kg} /$ $\mathrm{m}^{2}$ (range $\left.16-48 \mathrm{~kg} / \mathrm{m}^{2}\right)$ ) and pre-DM $\left(27 \mathrm{~kg} / \mathrm{m}^{2}\right.$ (range $\left.\left.15-47 \mathrm{~kg} / \mathrm{m}^{2}\right)\right)$ than in patients without these disorders $\left(\left(24 \mathrm{~kg} / \mathrm{m}^{2}\right.\right.$ (range $\left.14-53 \mathrm{~kg} / \mathrm{m}^{2}\right)$ and $24 \mathrm{~kg} / \mathrm{m}^{2}$ (range $\left.14-53 \mathrm{~kg} / \mathrm{m}^{2}\right)$, respectively) $)(\mathrm{p} \leq 0.001)$. More patients with DM (33\%; $\mathrm{p}=0.002)$ and pre-DM (31\%; $\mathrm{p}<0.001)$, suffered from obesity (BMI $\geq 30 \mathrm{~kg} / \mathrm{m}^{2}$ ) compared with patients with none of these disorders $(15 \%)$.

Seventy-six patients $(8 \%)$ were underweight with no difference in distribution comparing patients with DM and pre-DM with patients without these disorders $(\mathrm{p}>0.5$ for all). In patients with DM and pre-DM, both systolic and diastolic BP were significantly higher than in patients without these disorders $(\mathrm{p}<0.001$ for all).

Median hemoglobin was $127 \mathrm{~g} / \mathrm{L}$ (range 44-220g/L). Overall, anemia was seen in $36 \% \quad(n=333)$ and no differences in distribution were seen between patients with DM and without $\mathrm{DM} / \mathrm{pre}-\mathrm{DM}(\mathrm{p}=0.883)$. In patients with pre$\mathrm{DM}$, anemia was more frequent compared with patients without the disorder $(\mathrm{p}=0.016)$. Sixty-three patients $(6.2 \%)$ had HIV without significant difference in distribution according to glucose metabolism status. Overall, acute infection was seen in 9\% ( $\mathrm{n}=89)$ and more frequent in patients with pre-DM than in patients without the disorder ( $13 \%$ vs $8 \%$; $p=0.025)$. In patients with $\mathrm{DM}$ and in patients without $\mathrm{DM} / \mathrm{pre}-\mathrm{DM}$, the cases of acute infection were equally distributed ( $10 \%$ vs $8 \%$; $\mathrm{p}=0.346)$. Seventy-six patients $(8 \%)$ had a history of smoking without differences in distribution according to glucose metabolism.

Albumin-creatinine ratio was higher in patients with DM $(14 \mathrm{mg} / \mathrm{g}$ (range $2-852 \mathrm{mg} / \mathrm{g}) ; \mathrm{p}<0.001)$ and pre-DM $(7 \mathrm{mg} / \mathrm{g}$ (range $2-353 \mathrm{mg} / \mathrm{g}) ; \mathrm{p}=0.009)$ than in patients with none of these disorders $(6 \mathrm{mg} / \mathrm{g}$ (range 1-999); $\mathrm{p} \leq 0.009)$. Estimated GFR was lower in patients with DM $\left(110 \mathrm{~mL} / \mathrm{min} / 1.73 \mathrm{~m}^{2}\right.$ (range $\left.47-181\right)$ ) and pre-DM $\left(117 \mathrm{~mL} / \mathrm{min} / 1.73 \mathrm{~m}^{2}\right.$ (range $\left.12-202\right)$ ) than in patients without these disorders $\left(130 \mathrm{~mL} / \mathrm{min} / 1.73 \mathrm{~m}^{2}\right.$ (range 5-220); $\mathrm{p}<0.001$ for all)) (table 1 ).

\section{Prevalence rates of diabetes (DM), prediabetes (pre-DM) and} impaired glucose metabolism (IGM) across age-groups and body mass index (BMI) categories

Overall prevalence rates for DM, pre-DM, and IGM were $6.8 \%$ (95\% CI $5.3 \%$ to $8.5 \%$ ), $25 \%$ (95\% CI $22.8 \%$ to $28.3 \%$ ), and $32 \%$ (95\% CI $28.6 \%$ to 34.6 ), respectively (table 2). In patients with DM, $85 \%(57 / 67)$ had an HbAlc $\geq 6.5 \%(\geq 48 \mathrm{mmol} / \mathrm{mol})$. Sixty per cent $(40 / 67)$ had a known history of DM, of whom $57 \%$ (23/40) were treated by antidiabetics (not shown in table 2).

Prevalence rates increased across age decades (from age group 18-29 to $\geq 60$ years) for DM, pre-DM, and IGM reaching from $2.2 \%$ (95\% CI $0.9 \%$ to $4.4 \%$ ) to $18.5 \%$ (95\% CI $12.2 \%$ to $26.2 \%$ ), from $15.6 \%$ (95\% CI $11.8 \%$ to $20.0 \%$ ) to $35.4 \%$ (95\% CI $28.6 \%$ to $45.8 \%$ ), and from 
Table 1 Patients characteristics in patients with diabetes and prediabetes

\begin{tabular}{|c|c|c|c|c|c|c|c|}
\hline & Overall & Diabetes & $\begin{array}{l}\text { No diabetes+no } \\
\text { prediabetes }\end{array}$ & $P$ value & Prediabetes & $\begin{array}{l}\text { No diabetes+no } \\
\text { prediabetes }\end{array}$ & $P$ value \\
\hline Overall & 992 & $67(9 \%)$ & $678(91 \%)$ & & $247(27 \%)$ & $678(27 \%)$ & \\
\hline Male vs & $301(30 \%)$ & $20(9 \%)$ & $214(91 \%)$ & & $67(22 \%)$ & $234(78 \%)$ & \\
\hline Female & $691(70 \%)$ & $47(9 \%)$ & $464(91 \%)$ & 0.928 & $180(26 \%)$ & $511(74 \%)$ & 0.205 \\
\hline Age (years) & $36(18-91)$ & $54(19-91)$ & $34(18-91)$ & $<0.001^{*}$ & $44(18-89)$ & $33(18-84)$ & $<0.001^{*}$ \\
\hline BMI $\left(\mathrm{kg} / \mathrm{m}^{2}\right) \ddagger$ & $23(14-53)$ & $27(16-48)$ & $24(14-53)$ & $0.001^{*}$ & $27(15-47)$ & $24(14-53)$ & $<0.001^{*}$ \\
\hline $\mathrm{BMl}<18.5$ & $76(8 \%)$ & $6(9.0 \%)$ & $53(8 \%)$ & $0.858 \dagger$ & $17(7 \%)$ & $53(8 \%)$ & $0.689 \dagger$ \\
\hline BMI 18.5-24.9 & $475(48 \%)$ & $17(25 \%)$ & $361(53 \%)$ & $<0.001 \dagger$ & 97 (39\%) & $361(53 \%)$ & $<0.001 \dagger$ \\
\hline BMI 25-29.9 & $236(24 \%)$ & $22(32 \%)$ & $158(23 \%)$ & $0.199 \dagger$ & $56(23 \%)$ & $158(23 \%)$ & 0.789 \\
\hline $\mathrm{BMI} \geq 30$ & $202(20 \%)$ & 22 (33\%) & $103(15 \%)$ & $0.002 \dagger$ & 77 (31\%) & $103(15 \%)$ & $<0.001 \dagger$ \\
\hline BP systolic $(\mathrm{mm} \mathrm{Hg}) \S$ & $120(70-286)$ & 140 (92-242) & $120(70-286)$ & $<0.001^{*}$ & $132(72-250)$ & $120(70-286)$ & $<0.001^{*}$ \\
\hline BP diastolic $(\mathrm{mm} \mathrm{Hg}) \uparrow$ & $80(36-150)$ & $90(42-140)$ & $80(36-140)$ & $<0.001^{*}$ & $80(48-150)$ & $80(36-140)$ & $<0.001^{*}$ \\
\hline $\mathrm{HbA1c}(\%)$ & $5.4(3.9-14)$ & $7.2(4.9-14)$ & $5.2(3.9-5.6)$ & $<0.001^{*}$ & $5.9(5.7-6.4)$ & $5.2(3.9-5.6)$ & $<0.001^{*}$ \\
\hline $\mathrm{HbA} 1 \mathrm{c}<5.7 \%(<39 \mathrm{mmol} / \mathrm{mol})$ & $682(69 \%)$ & $3(5 \%)$ & $678(99 \%)$ & $<0.001 \dagger$ & $0(0 \%)$ & $678(100 \%)$ & $<0.001 \dagger$ \\
\hline $\begin{array}{l}\mathrm{HbA} 1 \mathrm{c} 5.7 \%-6.49 \% \text { (39- } \\
47 \mathrm{mmol} / \mathrm{mol})\end{array}$ & $253(25 \%)$ & $6(9 \%)$ & $0(0 \%)$ & $<0.001 \dagger$ & $247(100 \%)$ & $0(0 \%)$ & $<0.001 \dagger$ \\
\hline $\mathrm{HbA} 1 \mathrm{c} \geq 6.5 \%(\geq 48 \mathrm{mmol} / \mathrm{mol})$ & $57(6 \%)$ & $57(85 \%)$ & $0(0 \%)$ & $<0.001 \dagger$ & $0(0 \%)$ & $0(0 \%)$ & 1.0 \\
\hline Hemoglobin (g/L) & $127(44-220)$ & $132(68-153)$ & $128(44-220)$ & $0.309^{*}$ & $124(60-168)$ & $128(41-220)$ & $0.001^{*}$ \\
\hline Anemia $(\mathrm{WHO})^{\star \star}$ & $333(36 \%)$ & $18(33 \%)$ & $216(34 \%)$ & $0.883 \dagger$ & $99(43 \%)$ & $216(34 \%)$ & $0.016 \dagger$ \\
\hline HIV positive†† & $63(6 \%)$ & $3(4 \%)$ & $23(6 \%)$ & $0.789 \dagger$ & $18(7 \%)$ & $42(6 \%)$ & $0.548 \dagger$ \\
\hline Acute infection $\ddagger \ddagger$ & $89(9 \%)$ & $7(10 \%)$ & $51(8 \%)$ & $0.346 \dagger$ & $31(13 \%)$ & $51(8) \%$ & $0.025 \dagger$ \\
\hline History of smoking & $76(8 \%)$ & $5(7 \%)$ & $55(8 \%)$ & $1.0 \dagger$ & $16(6 \%)$ & $55(8 \%)$ & $0.486 \dagger$ \\
\hline ACR mg/g§§ & 7 (1-999) & $14(2-852)$ & $6(1-999)$ & $<0.001^{*}$ & $7(2-353)$ & $6(1-999)$ & $0.009^{*}$ \\
\hline Albuminuria $A C R \geq 30(\mathrm{mg} / \mathrm{g})$ & $126(13 \%)$ & $20(30 \%)$ & $70(10 \%)$ & $<0.001^{*}$ & $36(15 \%)$ & $70(10 \%)$ & $0.080^{*}$ \\
\hline eGFR (ml/min $\left./ 1.73 \mathrm{~m}^{2}\right)$ ๆ & $125(5-220)$ & $110(47-181)$ & $130(5-220)$ & $<0.001^{*}$ & $117(12-202)$ & $130(5-220)$ & $<0.001^{*}$ \\
\hline eGFR $\geq 90\left(\mathrm{ml} / \mathrm{min} / 1.73 \mathrm{~m}^{2}\right)$ & $854(88 \%)$ & $55(82 \%)$ & $595(92 \%)$ & $0.360 \dagger$ & $204(83 \%)$ & $595(88 \%)$ & $0.051 \dagger$ \\
\hline eGFR $60-89\left(\mathrm{ml} / \mathrm{min} / 1.73 \mathrm{~m}^{2}\right)$ & $94(10 \%)$ & $9(13 \%)$ & $52(9 \%)$ & $0.160 \dagger$ & $33(13 \%)$ & $52(8 \%)$ & $0.014 \dagger$ \\
\hline eGFR $<60\left(\mathrm{ml} / \mathrm{min} / 1.73 \mathrm{~m}^{2}\right)$ & $24(2 \%)$ & $3(4 \%)$ & $13(2 \%)$ & $0.176 \dagger$ & $8(3 \%)$ & $13(2 \%)$ & $0.318 \dagger$ \\
\hline
\end{tabular}

Data are displayed as counts and (per cent) or median and (range).

*Mann-Whitney-U (rank sum) test.

†Fisher's exact test.

‡BMl: underweight $\left(B M l<18.5 \mathrm{~kg} / \mathrm{m}^{2}\right)$, normal weight (BMl 18.5-24.9 $\left.\mathrm{kg} / \mathrm{m}^{2}\right)$, overweight $\left(\mathrm{BMl} 25-29.9 \mathrm{~kg} / \mathrm{m}^{2}\right)$, obesity $\left(\mathrm{BMl} \geq 30 \mathrm{~kg} / \mathrm{m}^{2}\right)$ were defined according to WHO BMI reference standards.

§BP systolic: blood pressure systolic.

IBP diastolic: blood pressure diastolic.

${ }^{* *}$ Anemia according to WHO: ${ }^{25}<120 \mathrm{~g} / \mathrm{L}$ female, $<130 \mathrm{~g} / \mathrm{L}$ male.

††HIV positive: 42 patients were diagnosed with HIV by testing within the study, 21 patients had a history of HIV, and 19 of them were on antiretroviral therapy.

¥¥Acute infection: acute systemic infection/inflammation or possible UTI, that is, body temperature of $\geq 38.5^{\circ} \mathrm{C}$ (armpit), acute malaria, acute TB,

leukocyte count $>20 /$ HPF in urinary sediment or newly positive tested HIV cases.

$\S \S A C R$ : albumin-to-creatinine ratio; Albuminuria: $A C R \geq 30 \mathrm{mg} / \mathrm{g}$.

१ๆ leGFR: estimated glomerular filtration rate with CKD-EPI formula. ${ }^{20}$

$\mathrm{BMI}$, body mass index; CKD-EPI, chronic kidney disease epidemiology collaboration; TB, tuberculosis; UTI, urinary tract infection.

$17.8 \%$ (95\% CI $13.7 \%$ to $22.4 \%$ ) to $53.9 \%$ (95\% CI $44.9 \%$ to $62.6 \%$ ), respectively, (table 2 ). There was a significant increase in DM prevalence rates in patients 50-59 and $\geq 60$ years old and in pre-DM prevalence rates in patients $40-49,50-59$, and $\geq 60$ years old compared with patients $18-29$ years old, respectively ( $\mathrm{p}<0.001$ for all) (figure $1 \mathrm{~A})$.

The prevalence rates across BMI categories are depicted in table 2. Prevalence rates in underweight patients for DM, pre-DM, and IGM were $7.9 \%$ (95\% CI $2.9 \%$ to $16.3 \%$ ), $22.4 \%$ (95\% CI $13.6 \%$ to $23.4 \%$ ), and
$30.3 \%$ (95\% CI $20.2 \%$ to $41.9 \%$ ), respectively. Prevalence rates increased across BMI categories (from normal weight to obesity) for DM, pre-DM, and IGM reaching from $3.6 \%$ (95\% CI $2.1 \%$ to $5.6 \%$ ) to $10.9 \%$ (95\% CI $6.9 \%$ to $16.0 \%$ ), from $20.4 \%$ (95\% CI $16.9 \%$ to $24.9 \%$ ) to $38.1 \%$ (95\% CI $31.4 \%$ to $45.2 \%$ ), and from $24 \%$ (95\% CI $20.2 \%$ to $28.1 \%$ ) to $49.0 \%$ (95\% CI 41.9 to 56.1 ), respectively (table 2).

There was a significant increase in DM prevalence rates in patients with overweight $(p<0.01)$ and obesity 
Table 2 Diabetes, prediabetes, and impaired glucose metabolism prevalence rates across age-groups and BMI categories

\begin{tabular}{|c|c|c|c|c|c|c|}
\hline & \multirow[b]{2}{*}{$\mathbf{N}$} & \multirow{2}{*}{$\begin{array}{l}\text { Diabetes prevalence } \\
\text { rates } \\
\%(95 \% \mathrm{Cl})\end{array}$} & \multirow[b]{2}{*}{$\mathbf{N}$} & \multirow{2}{*}{$\begin{array}{l}\begin{array}{l}\text { Prediabetes } \\
\text { prevalence rates }\end{array} \\
\%(95 \% \mathrm{Cl})\end{array}$} & \multirow[b]{2}{*}{$\mathbf{N}$} & \multirow{2}{*}{$\begin{array}{l}\text { Impaired glucose } \\
\text { metabolism prevalence } \\
\text { rates } \\
\%(95 \% \mathrm{Cl})\end{array}$} \\
\hline & & & & & & \\
\hline \multicolumn{7}{|c|}{ Age category (years) } \\
\hline $18-29$ & 7 & 2.18 (0.9 to 4.4$)$ & 50 & 15.58 (11.8 to 20.0$)$ & 57 & 17.76 (13.7 to 22.4$)$ \\
\hline 30-39 & 7 & 3.03 (1.2 to 6.1$)$ & 42 & 18.18 (13.8 to 24.2 ) & 49 & 21.21 (16.1 to 27.0 ) \\
\hline $40-49$ & 11 & 6.01 (3.0 to 10.5) & 61 & 33.33 (27.1 to 41.2 ) & 72 & 39.34 (32.2 to 46.8$)$ \\
\hline $50-59$ & 18 & 14.87 (9.1 to 22.5$)$ & 47 & 38.84 (31.7 to 49.8 ) & 65 & 53.72 (44.4 to 62.8$)$ \\
\hline$\geq 60$ & 24 & 18.46 (12.2 to 26.2 ) & 46 & 35.38 (28.6 to 45.8 ) & 70 & 53.85 (44.9 to 62.6$)$ \\
\hline Overall & 67 & 6.75 (5.3 to 8.5$)$ & 246 & 24.95 (22.8 to 28.3 ) & 314 & 31.74 (28.7 to 34.6$)$ \\
\hline \multicolumn{7}{|l|}{ BMI $\left(\mathrm{kg} / \mathrm{m}^{2}\right)$} \\
\hline$<18.5$ & 6 & 7.89 (2.9 to 16.3$)$ & 17 & 22.37 (13.6 to 33.4$)$ & 23 & 30.26 (20.2- to 41.9$)$ \\
\hline $18.5-24.9$ & 17 & 3.58 (2.1 to 5.6$)$ & 97 & 20.42 (16.9 to 24.3 ) & 114 & 24.00 (20.2 to 28.1$)$ \\
\hline $25-29.9$ & 22 & 9.32 (5.9 to 13.7 ) & 56 & 23.73 (18.5 to 29.6 ) & 78 & 33.05 (27.1 to 39.4$)$ \\
\hline$\geq 30$ & 22 & 10.89 (6.9 to 16.0$)$ & 77 & 38.12 (31.4 to 45.2$)$ & 99 & 49.01 (41.9 to 56.1$)$ \\
\hline Overall & 67 & 6.77 (5.3 to 8.5$)$ & 247 & 24.97 (22.8 to 28.3$)$ & 314 & 31.75 (28.6 to 34.6$)$ \\
\hline
\end{tabular}

Impaired glucose metabolism: patients with diabetes and prediabetes; $\mathrm{BMl}<18.5 \mathrm{~kg} / \mathrm{m}^{2}$ underweight, $\mathrm{BMl}=18.5-24.9 \mathrm{~kg} / \mathrm{m}^{2} \mathrm{normal}$ weight, $\mathrm{BMI}=25-29.9 \mathrm{~kg} / \mathrm{m}^{2}$ overweight, and $\mathrm{BMl} \geq 30 \mathrm{~kg} / \mathrm{m}^{2}$ obesity.

BMI, body mass index.

$(\mathrm{p}<0.01)$, and for pre-DM in obese patients $(\mathrm{p}<0.001)$ compared with patients with normal weight, respectively (figure 1A).

\section{Predictors for diabetes (DM)}

In univariate logistic regression analysis, older age (OR 1.07 per 1 year, $95 \%$ CI 1.05 to 1.08 ; $\mathrm{p}<0.001$ ), increasing BMI (OR 1.10 per $1 \mathrm{~kg} / \mathrm{m}^{2}, 95 \%$ CI 1.05 to 1.15 ; $\mathrm{p}<0.001$ ), increasing BP systolic (OR 1.02 per $1 \mathrm{~mm} \mathrm{Hg}$, 95\% CI 1.02 to $1.03 ; \mathrm{p}<0.001$ ), increasing $\mathrm{BP}$ diastolic (OR 1.04 per $1 \mathrm{~mm} \mathrm{Hg}, 95 \%$ CI 1.02 to $1.06 ; \mathrm{p}<0.001)$, and albuminuria (OR 4.18, 95\% CI 2.17 to 7.78 ; $\mathrm{p}<0.001$ ) were statistically significant predictors for DM. The OR for the presence of DM decreased with increasing eGFR (OR 0.98 per $1 \mathrm{~mL} / \mathrm{min} / 1.73 \mathrm{~m}^{2}, 95 \%$ CI 0.97 to $0.99 ; \mathrm{p}=0.001$ ).

In multivariate logistic regression analysis, older age (OR 1.08 per 1 year, $95 \%$ CI 1.05 to 1.12 ; $\mathrm{p}<0.001$ ), increasing BMI (OR 1.10 per $1 \mathrm{~kg} / \mathrm{m}^{2}, 95 \%$ CI 1.04 to $1.16 ; \mathrm{p}<0.001$ ), acute infection (OR 3.46, 95\% CI 1.02 to $10.8 ; \mathrm{p}=0.038$ ) and albuminuria (OR $3.63,95 \%$ CI 1.64 to 7.83; $\mathrm{p}=0.001$ ) were statistically significant predictors for DM (table 3 ).

\section{Predictors for prediabetes (pre-DM)}

In univariate logistic regression analysis, older age (OR 1.04 per 1 year, $95 \%$ CI 1.03 to 1.05 ; $\mathrm{p}<0.001$ ), increasing BMI (OR 1.08 per $1 \mathrm{~kg} / \mathrm{m}^{2}, 95 \%$ CI 1.05 to $1.11 ; \mathrm{p}<0.001$ ), increasing BP systolic (OR 1.01 per $1 \mathrm{~mm}$ $\mathrm{Hg}, 95 \% \mathrm{CI} 1.01$ to $1.02 ; \mathrm{p}<0.001)$ and increasing $\mathrm{BP}$ diastolic (OR 1.03 per $1 \mathrm{~mm} \mathrm{Hg}, 95 \%$ CI 1.02 to 1.04 ; $\mathrm{p}<0.001$ ) were statistically significant predictors for preDM. An increasing $\mathrm{Hb}$ (OR 0.90 per $1 \mathrm{~g} / \mathrm{dL}, 95 \% \mathrm{CI}$ 0.83 to $0.97 ; \mathrm{p}=0.004$ ) and the absence of anemia (OR
$0.69,95 \%$ CI 0.50 to $0.94 ; \mathrm{p}=0.019$ ) were associated with reduced risk for pre-DM. Further, the OR for the presence of pre-DM decreased with higher eGFR (OR 0.98 per $1 \mathrm{~mL} / \mathrm{min} / 1.73 \mathrm{~m}^{2}, 95 \%$ CI 0.98 to $0.99 ; \mathrm{p}<0.001$ ) (table 3 ).

In multivariate logistic regression analysis, older age (OR 1.03 per 1 year, 95\% CI 1.02 to 1.05 ; p<0.001), increasing BMI (OR 1.07 per $1 \mathrm{~kg} / \mathrm{m}^{2}, 95 \%$ CI 1.04 to $1.10 ; \mathrm{p}<0.001)$ and acute infection (OR 2.79, 95\% CI 1.46 to $5.30 ; \mathrm{p}=0.002)$ were significant predictors for prediabetes (table 3 ).

\section{Predictors for impaired glucose metabolism (IGM)}

In univariate logistic regression analysis, older age (OR 1.04 per 1 year, $95 \%$ CI 1.03 to 1.05 ; $\mathrm{p}<0.001$ ), increasing BMI (OR 1.08 per $1 \mathrm{~kg} / \mathrm{m}^{2}, 95 \%$ CI 1.06 to 1.11 ; $\mathrm{p}<0.001$ ), increasing BP systolic (OR 1.02 per $1 \mathrm{mmHg}, 95 \%$ CI 1.01 to $1.02 ; \mathrm{p}<0.001$ ), increasing $\mathrm{BP}$ diastolic (OR 1.03 per $1 \mathrm{mmHg}, 95 \%$ CI 1.02 to $1.04 ; \mathrm{p}<0.001$ ), acute infection (OR 1.63, 95\% CI 1.02 to 2.58; $\mathrm{p}=0.043$ ) and albuminuria (OR 1.86, 95\% CI 1.23 to $2.80 ; \mathrm{p}=0.004$ ) were statistically significant predictors for IGM. An increasing $\mathrm{Hb}$ (OR 0.91 per $1 \mathrm{~g} / \mathrm{dL}, 95 \%$ CI 0.85 to $0.98 ; \mathrm{p}=0.013$ ) and the absence of anemia (OR $0.74,95 \%$ CI 0.56 to 0.99 ; $\mathrm{p}=0.045$ ) were associated with reduced risk for IGM. Further, the OR for the presence of IGM decreased with higher eGFR (OR 0.98 per $1 \mathrm{~mL} / \mathrm{min} / 1.73 \mathrm{~m}^{2}, 95 \%$ CI 0.98 to $0.99 ; \mathrm{p}<0.001$ ) (table 3 ).

In multivariate logistic regression analysis, older age (OR 1.04 per 1year, 95\% CI 1.03 to 1.05 ; p<0.001), increasing BMI (OR 1.07 per $1 \mathrm{~kg} / \mathrm{m}^{2}, 95 \%$ CI 1.04 to 1.10; $\mathrm{p}<0.001$ ) and acute infection (OR 2.99, 95\% CI 1.62 
A
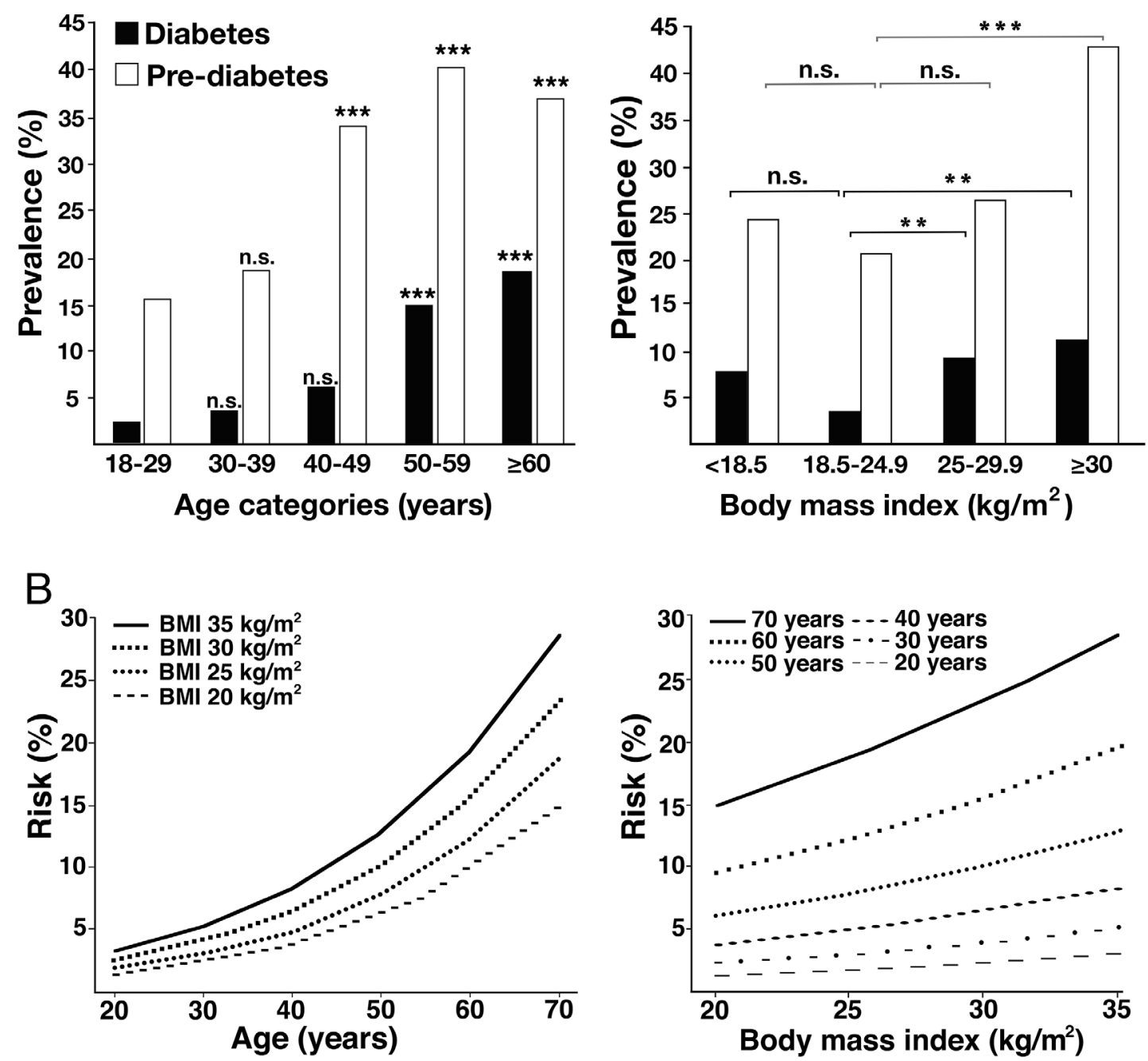

Figure 1 Effect of age and BMl on estimated prevalence and estimated risk for diabetes mellitus. (A) Effect of age and BMl on estimated prevalence; reference group $18-29$ years, ${ }^{* \star \star} p<0.001$, n.s.: non significant; reference group BMl $18.5-24.9 \mathrm{~kg} /$ $\mathrm{m}^{2},{ }^{* *} \mathrm{p}<0.01,{ }^{* \star *} \mathrm{p}<0.001$, n.s.: non significant. (B) Estimated risk for diabetes mellitus stratified by BMI across age groups and stratified by age across $\mathrm{BMI}$ categories. $\mathrm{BMl}<18.5 \mathrm{~kg} / \mathrm{m}^{2}$ underweight, $\mathrm{BMl}=18.5-24.9 \mathrm{~kg} / \mathrm{m}^{2}$ normal weight, $\mathrm{BMl}=25-29.9 \mathrm{~kg} /$ $\mathrm{m}^{2}$ overweight, and $\mathrm{BMl} \geq 30 \mathrm{~kg} / \mathrm{m}^{2}$ obesity. BMl, body mass index.

to $5.54 ; \mathrm{p}<0.001)$ were significant predictors for IGM (table 3 ).

\section{Effect of age and body mass index (BMI) on the estimated risk for diabetes}

Figure 1B illustrates the effect of age and BMI on the estimated risk of diabetes. Comparing patients with a BMI of $20 \mathrm{~kg} / \mathrm{m}^{2}$ and a BMI of $35 \mathrm{~kg} / \mathrm{m}^{2}$, the relative risk for DM increases in average by 2.12-fold (range 1.91-2.24) across the age groups. Comparing patients 20 years old with patients 70 years old, the relative risk for DM increases in average 9.7-fold (range 8.9-10.4) across the BMI groups (online supplementary table $\mathrm{S} 1$ ).

\section{Correlation of glycated hemoglobin (HbA1c) and hemoglobin (Hb) levels}

Overall, mean values of HbA1c did not differ in patients with $(5.58 \%$ (37 mmol $/ \mathrm{mol}) ; 95 \%$ CI $5.5 \%$ to $5.7 \%$ $(37-39 \mathrm{mmol} / \mathrm{mol}))$ and without anemia $(5.57 \% \quad(37$ $\mathrm{mmol} / \mathrm{mol}) ; 95 \%$ CI $5.5 \%$ to $5.7 \%(37-39 \mathrm{mmol} / \mathrm{mol})$; $\mathrm{p}=0.872$ ). Further, mean values of HbAlc values $\geq 6.5 \%$ $(\geq 48 \mathrm{mmol} / \mathrm{mol}) \quad(\mathrm{n}=47)$ did not differ in patients with $(8.88 \%$ (74 mmol $/ \mathrm{mol}) ; 95 \%$ CI $7.2 \%$ to $10.5 \%$ $(55-91 \mathrm{mmol} / \mathrm{mol}))$ and without anemia $(9.03 \%$ (75 $\mathrm{mmol} / \mathrm{mol}) ; 95 \% \mathrm{CI} 8.1 \%$ to $10.0 \%(65-86 \mathrm{mmol} / \mathrm{mol})$; $\mathrm{p}=0.859$ ). In males (all), mean $\mathrm{HbA1c}$ value was higher in males with $(5.88 \%(41 \mathrm{mmol} / \mathrm{mol}) ; 95 \%$ CI $5.4 \%$ to $6.3 \%(36-45 \mathrm{mmol} / \mathrm{mol}))$ compared with males without anemia $(5.48 \%$ (36 mmol $/ \mathrm{mol}) ; 95 \%$ CI $5.4 \%$ to $5.6 \%$ $(36-38 \mathrm{mmol} / \mathrm{mol}) ; \mathrm{p}=0.024)$. There was no significant difference in females with and without anemia in mean HbA1c value ( $\mathrm{p}=0.28$ ) (online supplementary table $\mathrm{S} 2$ ).

Pearson's correlation between HbA1c levels and hemoglobin levels is depicted in figure 2. For the whole population, the Pearson's correlation coefficient between HbA1c and Hb levels was $\mathrm{r}=-0.009(\mathrm{p}=0.779)$; in males, it was $\mathrm{r}=-0.132(\mathrm{p}=0.028)$; in females, it was $\mathrm{r}=0.062$ 


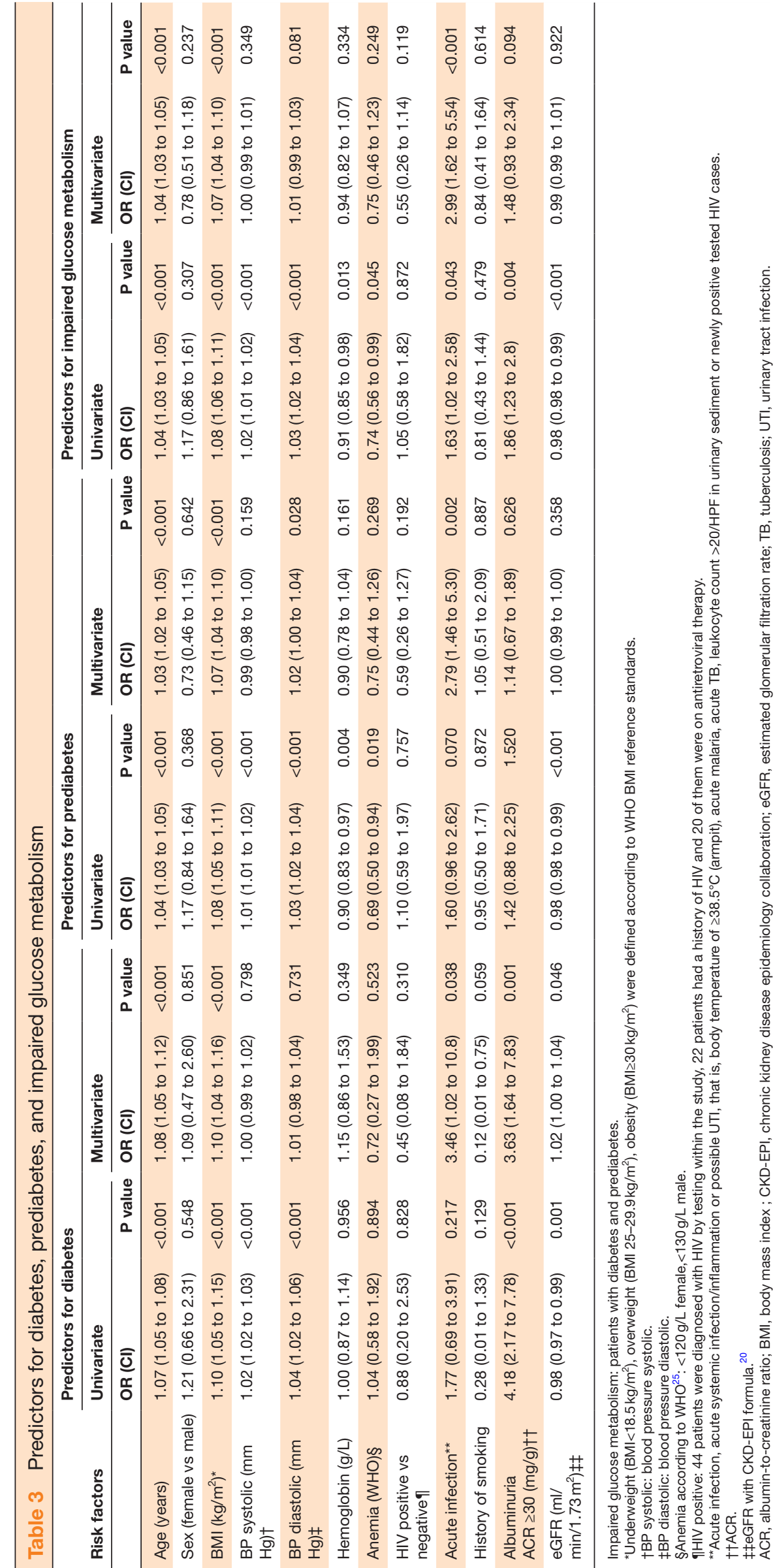


A
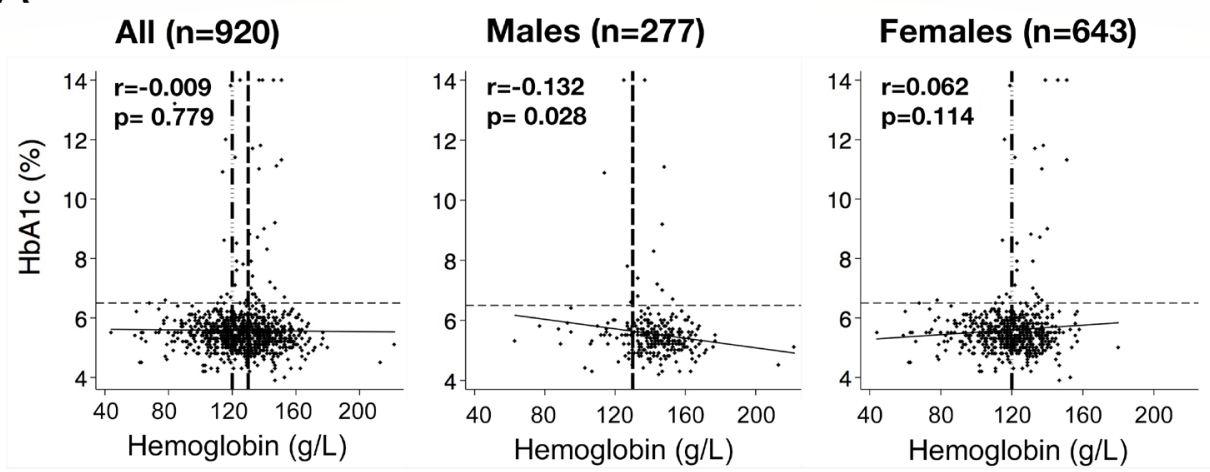

\section{$\mathrm{DM}(\mathrm{n}=55)^{\star}$}

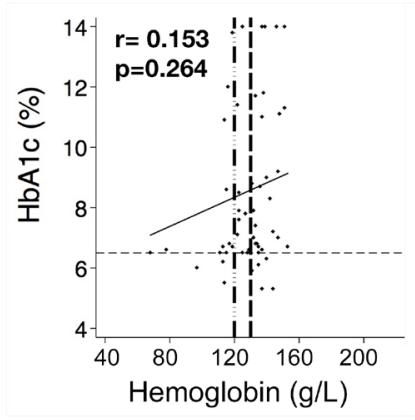

pre-DM $(\mathrm{n}=230)+$

FBG ( $n=212) \neq$
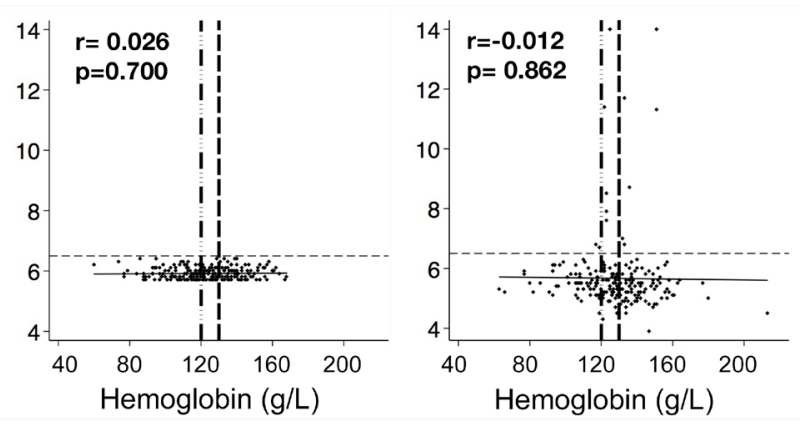

B
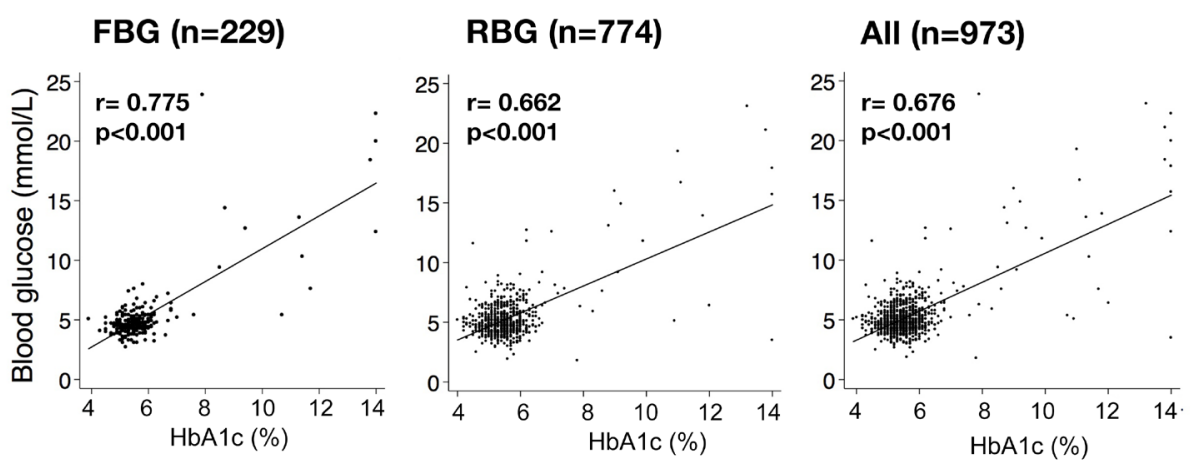

Figure 2 Pearson's correlation of HbA1c with hemoglobin and blood glucose values. (A) Pearson's correlation of HbA1c with hemoglobin; r: Pearson's correlation coefficient (r); black solid line: fitted values of correlation between HbA1c (\%) and hemoglobin (g/L); black thin dashed line: HbA1c $6.5 \%$ (cut-off to diagnose DM); ${ }^{4}$ vertical dashed lines with dots: WHO anemia cut-off levels for males (130 g/L); ${ }^{25}$ vertical dashed lines without dots: WHO anemia cut-off levels for females $(120 \mathrm{~g} / \mathrm{L}) ;{ }^{25}$ missing hemoglobin: ${ }^{*} n=12,\lceil n=17, \neq n=19$. (B) Pearson's correlation of HbA1c and blood glucose values; black solid line: fitted values of correlation between HbA1c (\%) and blood glucose (mmol/L). DM, diabetes; FBG, fasting blood glucose; pre-DM, prediabetes; RBG, random blood glucose.

$(\mathrm{p}=0.114)$; in the subgroup of patients with DM, it was $\mathrm{r}=0.153(\mathrm{p}=0.264)$, with pre-DM, it was $\mathrm{r}=0.026(\mathrm{p}=0.700)$, and with fasting blood glucose (FBG), it was $\mathrm{r}=-0.012$ $(\mathrm{p}=0.862)$ (figure $2 \mathrm{~A})$.

\section{Correlation of glycated hemoglobin (HbA1c) and blood glucose values}

In 23\% ( $\mathrm{n}=229)$ of the population FBG was measured, the Pearson's correlation coefficient between HbAlc and FBG was $\mathrm{r}=0.775 \quad(\mathrm{p}<0.001)$. In the remaining patients ( $\mathrm{n}=744)$, a RBG was measured and the Pearson's correlation coefficient for HbA1c and RBG was $r=0.662$ $(\mathrm{p}<0.001)$. The correlation coefficient between HbA1c and all blood glucose values $(\mathrm{n}=973)$ was $\mathrm{r}=0.676$ $(\mathrm{p}<0.001)$ (figure 2B).

\section{Correlation of glycated hemoglobin (HbA1c) and blood glucose values in different stages of glucose metabolism}

In patients with both $\mathrm{HbA1c}$ and $\mathrm{BG}$ (FBG or $\mathrm{RBG}$ ) values in the diabetic range $(n=24)$, median $B G$ was numerically higher $(14.7 \mathrm{mmol} / \mathrm{L}$; inter quartile range (IQR) $6.4 \mathrm{mmol} / \mathrm{L})$ than in patients in whom only BG $(\mathrm{n}=6)$ 
was in the diabetic range $(9.8 \mathrm{mmol} / \mathrm{L}$; IQR $4.2 \mathrm{mmol} / \mathrm{L})$ $(\mathrm{p}=0.443)$. In patients with only HbA1c in the diabetic range $(\mathrm{n}=33)$, median $\mathrm{BG}$ was lower $(5.8 \mathrm{mmol} / \mathrm{L}$; IQR $1.5 \mathrm{mmol} / \mathrm{L}$ ) than in patients with both $\mathrm{HbA1c}$ and $\mathrm{BG}$ in the diabetic range $(14.7 \mathrm{mmol} / \mathrm{L}$; IQR $6.4 \mathrm{mmol} / \mathrm{L})$ $(\mathrm{p}<0.001)$, but higher than in patients without IGM $(4.7 \mathrm{mmol} / \mathrm{L} ; \mathrm{IQR} 1.0 \mathrm{mmol} / \mathrm{L}) \quad(\mathrm{p}<0.001)$ (figure $3 \mathrm{~A}$ and included table a).

In patients with both $\mathrm{HbAlc}$ and $\mathrm{BG}$ (FBG or RBG) values in the diabetic range $(\mathrm{n}=24)$, median HbAlc was numerically higher ( $11.2 \%$; IQR $4.9 \%$ (99 mmol $/ \mathrm{mol}$; IQR $30 \mathrm{mmol} / \mathrm{mol})$ ) than in patients in whom only HbA1c $(n=33)$ was in the diabetic range $(6.8 \%$, IQR $1.2 \%(51 \mathrm{mmol} / \mathrm{mol}))(\mathrm{p}<0.344)$. In patients with only $\mathrm{BG}$ in the diabetic range $(\mathrm{n}=6)$, median HbAlc was lower (5.7\%; IQR $0.9 \%(39 \mathrm{mmol} / \mathrm{mol}))$ than in patients with both $\mathrm{HbAlc}$ and BG in the diabetic range $(11.2 \%$; IQR $4.9 \%(99 \mathrm{mmol} / \mathrm{mol}$; IQR $30 \mathrm{mmol} / \mathrm{mol}))(\mathrm{p}<0.001)$, but higher than in patients without IGM (5.2\%; IQR 0.5\% (33 $\mathrm{mmol} / \mathrm{mol})$ ) $(\mathrm{p}<0.001)$ (figure $3 \mathrm{~B}$ and included table $\mathrm{b})$.

The corresponding results in patients with values in the prediabetic range and in patients with values in the range of IGM are depicted in figure $3 \mathrm{C} \mathrm{F}$ and in the included tables c-f.

\section{DISCUSSION}

In our study $31.8 \%$ of the patients had an IGM, which is composed of a high overall DM prevalence of $6.8 \%$ and a dramatic high pre-DM prevalence of $25 \%$. Prevalence rates and risk for DM were strongly dependent on BMI and age. In addition, we provide further evidence that HbAlc testing appears suitable for the diagnosis of DM in black African populations, even if anemia is highly prevalent.

The observed overall DM prevalence rate of $6.8 \%$ was as high as the age adjusted DM prevalence rate reported for Europe by the IDF in $2017^{4}$ and is advancing towards prevalence rates reported in recent years for the USA $(9.4 \%)$ and Canada $(7.4 \%) .{ }^{427}$

However, in SSA, data remain scarce for many countries and heterogenic throughout, ${ }^{4}$ especially due to differences in life and demographic conditions, and diagnostics standards. ${ }^{6} 79112829$ Thirty years ago, the estimated DM prevalence was as low as $1 \%$ in rural Tanzania. ${ }^{7}$ As observed in our study in the following years, a trend of rising numbers was seen and DM prevalence rates around $5 \%-7 \%$ were reported in populations with proceeding age from Tanzania and its neighboring countries Kenya and Uganda. 9112829

Little is still known about the frequency of pre-DM in populations from SSA. Reported prevalence rates vary between 3\% and 25\%. ${ }^{11} 283031$ In recently published nation-wide, population-based surveys from Kenya and Uganda, a pre-DM prevalence of around 3\% was reported. ${ }^{30}{ }^{31}$ Findings from surveys in northern Tanzania $(16 \%)$ and Uganda (20\%) are reporting larger rates, depending on the population and methodology. ${ }^{11}{ }^{28} \mathrm{We}$ found a very high pre-DM prevalence of $25 \%$. The risk to suffer from IGM might be higher in a walk-in population than in a general population, for which reason the data are not generalizable. However, as pre-DM is a strong risk factor for the development of DM, the finding is alarming despite this limitation. ${ }^{21} 32$

In our population, there was an impressively strong rise in DM prevalence with increasing age and BMI, especially after the age of 50 years and a BMI above $25 \mathrm{~kg} / \mathrm{m}^{2}$. For pre-DM, the same observation was made for patients a decade younger with a prevalence of more than $30 \%$ beginning at the age of 40 years. This finding supports the observation that pre-DM is a forerunner for DM. ${ }^{21} 32$

The relevance of age and BMI is also reflected by the increasing relative risk for DM, which is nearly 10 -fold higher in 70-year-old than in 20-year-old patients and on average twofold higher, if a patient presents a BMI of $35 \mathrm{~kg} / \mathrm{m}^{2}$ compared with a patient with BMI $20 \mathrm{~kg}$ / $\mathrm{m}^{2}$. This is of great relevance in the setting of SSA where the pandemic of excess bodyweight remains ongoing and life expectancy is increasing steadily over the last two decades, reaching more than 65 years in Tanzania in 2016. ${ }^{133}$ However, the populations in developing regions are exposed to both extremes, obesity and underweight, as can also be observed in our population with a prevalence of almost $10 \%$ underweight patients. In the literature, an association between malnutrition and diabetes is discussed, which is also referred to as malnutrition-related or malnutrition-modulated diabetes. ${ }^{9}{ }^{15334}$ However, the pathogenesis is not very well understood and epidemiological data are still missing. ${ }^{34}$ In our data, a J-shaped distribution of DM rates along the BMI scale could be observed, which supports the existence of the entity of a malnutrition-related diabetes. Unfortunately, we have no data on the causes of underweight in our population that could help to better understand the underlying pathophysiological processes.

Besides increasing age and BMI, acute infection was a further predictor for IGM. This is in line with the known bidirectional interaction between infectious disease and IGM. ${ }^{35}{ }^{36} \mathrm{DM}$ is associated with immune-dysregulation and increased susceptibility to infections, ${ }^{36}$ and infectious conditions contribute to the dysregulation of the glucose metabolism. ${ }^{37}$ Therefore, particularly in SSA, where endemic infectious diseases remain highly prevalent, ${ }^{38} 39$ the growing DM pandemic will further contribute to the "double burden of disease" and take its toll on the populations well-being and the health systems. ${ }^{17} 3740$

Testing HbAlc offers advantages and conveniences, such as preanalytical stability, better reproducibility and no requirement for fasting. ${ }^{1341}$ A quick point-of-care test without fasting requirements might be very useful in the setting of semirural SSA. ${ }^{33}$

A decade ago, an expert panel reported that HbAlc testing for DM diagnosis is limited in patients with anemia, ${ }^{42}$ due to a more rapid erythrocyte turnover, ${ }^{16}{ }^{42}$ which lowers the non-enzymatic glycosylation of $\mathrm{Hb}$ and decreases the HbA1c level in such patients. ${ }^{16} 43$ In our 


\section{Diabetes}

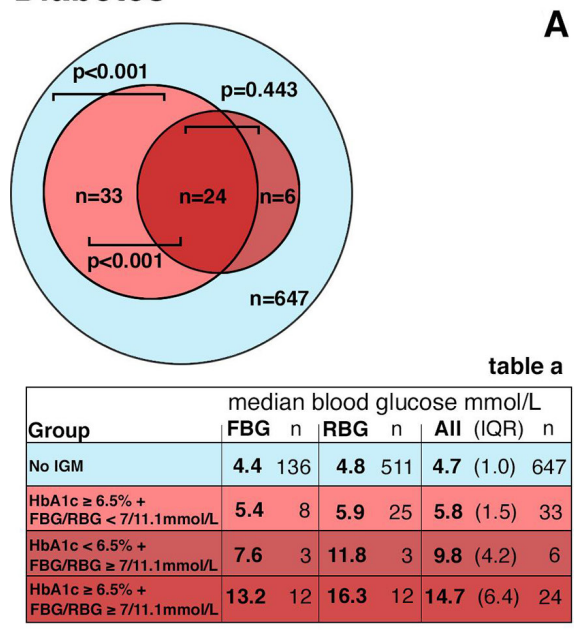

\section{Pre-diabetes}
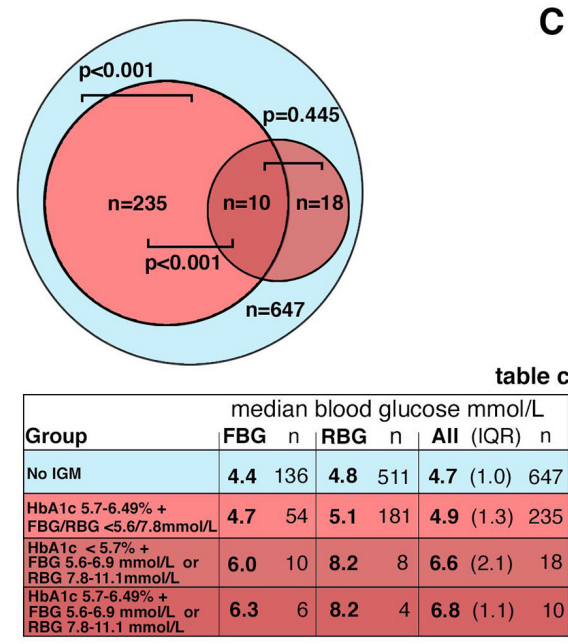

\section{Impaired glucose metabolism}

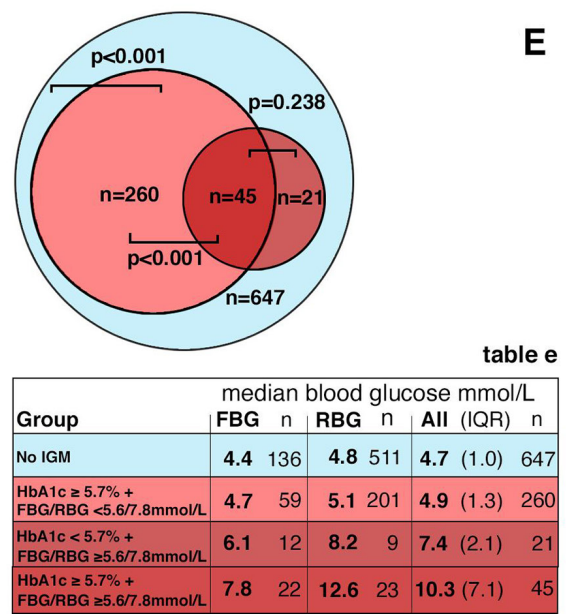

A

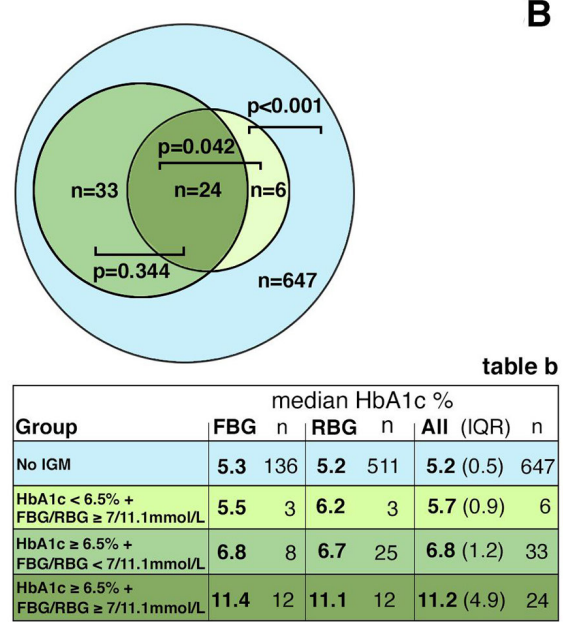

Figure 3 Venn diagram of median blood glucose and median HbA1c values in ranges of diabetes, prediabetes, and impaired glucose metabolism. Venn diagram: Median blood glucose levels (A,C,E) and median HbA1c levels (B,D,F) stratified by concordance and discordance between $\mathrm{HbA1c}$ levels and blood glucose levels in patients with values in diabetic range $(\mathrm{HbA} 1 \mathrm{c} \geq 6.5 \%$ or $\mathrm{FBG} \geq 7 \mathrm{mmol} / \mathrm{L}$ or $\mathrm{RBG} \geq 11.1 \mathrm{mmol} / \mathrm{L})$, in patients with values in prediabetic range $(\mathrm{HbA} 1 \mathrm{c}$ $5.7 \%-6.49 \%$ or FBG $5.6-6.9 \mathrm{mmol} / \mathrm{L}$ or RBG $7.8-11.1 \mathrm{mmol} / \mathrm{L})$, and in patients with values in the range of impaired glucose metabolism ( $\mathrm{HbA} 1 \mathrm{c} \geq 5.7 \%$ or $\mathrm{FBG} \geq 5.6 \mathrm{mmol} / \mathrm{L}$ or $\mathrm{RBG} \geq 7.8 \mathrm{mmol} / \mathrm{L})$ and no $\mathrm{IGM}(\mathrm{HbA} 1 \mathrm{c}<5.7 \%$ and $\mathrm{FBG}<5.6 \mathrm{mmol} / \mathrm{L}$ or $\mathrm{RBG}<7.8 \mathrm{mmol} / \mathrm{L}) .^{21}{ }^{24}$ Tables a-f: corresponding tables to Venn diagrams A-F. P values according to Dunn's test with Holm adjustment for pairwise comparison. BG, blood glucose; FBG, fasting blood glucose; HbA1c, glycated hemoglobin; IGM, impaired glucose metabolism; IQR: interquartile range (Q3-Q1); RBG, random blood glucose. 
analyses, there was no evidence of a relevant interaction in the whole population as well as in the explored subgroups between HbAlc and $\mathrm{Hb}$ values. Only in the subgroup of men a statistically significant correlation was observed. However, the correlation was very weak, and-other than one would expect-reversed, that is, men with anemia had higher HbAlc levels than men without anemia. This is in line with findings from data analyzed from the National Health and Nutrition Examination Survey (NHANES) 1999-2002, where only marginal effects between $\mathrm{HbA1c}$ concentration and $\mathrm{Hb}$ were observed. ${ }^{43}$

We could further show that there was a strong correlation and a clear "dose dependent" relationship between HbA1c levels and FBG as well as RBG values. The highest HbA1c values were observed in patients who had also FBG or RBG values in the diabetic range. In discordant pairs in which only HbA1c was in the diabetic range, FBG and RBG were lower, but still clearly higher than in the population with normal HbAlc values. Vice versa, in the few cases in which only FBG or RBG were in the diabetic range and $\mathrm{HbA1c}$ values were not, the HbA1c levels were higher than the values of the normal population. This observation was also consistent in the prediabetic states and overall for all patients with IGM, even if it did not always reach the level of significance due to the small number of cases. The clear positive relationship between HbA1c and FBG and even RBG in a cross-sectional setting is astonishing, because the strength of HbAlc measurements lies in the reflection of glucose metabolism over the past few months and not in the correlation with random single BG measurements. The results underline that HbA1c is very valid and reliable to detect a disturbed glucose balance even in populations with a high proportion of anemia, such as those in SSA. Our findings are further supported by a recently published study, which found similar age-standardized DM prevalence estimates based on HbA1c, oral glucose tolerance test, and FBG in an urban black South African population. ${ }^{14}$ However, in this study, data on $\mathrm{Hb}$ levels and their impact on HbAlc levels were not explored. ${ }^{14}$

We face several limitations in our study. The IGM prevalence might be overestimated due to a single point HbAlc measurement. ${ }^{41}$ The generalizability of the results is limited, because the sample represents a population from the OPC and not the general population. Our data do not allow drawing definitive conclusions about causality and about the progression from pre-DM toward DM. Finally, we lack data to describe the underlying causes of anemia and their specific impact on HbAlc levels.

To conclude, by means of a semirural population from Tanzania, we confirm the trend of rising prevalence and the ongoing spread of the DM pandemic in SSA. Particularly, the relationship of increasing age and BMI and the very high rate of pre-DM is supporting the projection that the DM pandemic will continue. Therefore, strategies like "The 2016 Dar es Salaam-Call to Action on Diabetes and other non-communicable diseases" plan are urgently needed in SSA and put to practice. ${ }^{44}$ Finally, our data present evidence for the usefulness of HbAlc testing in populations from SSA affected by a large proportion of anemia. In a next step, intervention studies are needed to oppose the DM pandemic in SSA. Moreover, such a frame would offer the in-depth exploration and utility of $\mathrm{HbAlc}$ as longitudinal and monitoring tool in populations of SSA.

\section{Author affiliations}

${ }^{1}$ Medical Outpatient Department, Universitätsspital Basel, Basel, Switzerland

${ }^{2}$ Swiss Tropical and Public Health Institute, Basel, Switzerland

${ }^{3}$ Ifakara Health Institute, Dar es Salaam, Tanzania

${ }^{4}$ Medical Outpatient Department, Bagamoyo District Hospital, Bagamoyo, Tanzania

${ }^{5}$ Cantonal Hospital Sankt Gallen, St. Gallen, Switzerland

Acknowledgements We cordially thank Marcel Tanner from the Swiss Tropical and Public Health Institute and the University of Basel, for his assistance to facilitate this fruitful Tanzanian-Swiss-collaboration. We would like to thank Andreas Schötzau for his help in statistical analysis and his support in the data interpretation. Further, we would like to thank Marc Donath, Head of Endocrinology, Diabetes \& Metabolism of the University Hospital Basel, for discussion and interpretation of the results.

Contributors All authors made contributions to the study. NCH carried out the fieldwork in the laboratory and clinic, collected, entered and analyzed the data, wrote and illustrated the manuscript. MM designed the study, wrote and revised the manuscript, cleaned data and supervised the fieldwork. AH coordinated the fieldwork and the approval of ethical clearance, informed the Bagamoyo community authorities about the study, translated protocols from English to Swahili, and revised the manuscript. KR coordinated this study onsite and provided important intellectual content input for study design. GM was the laboratory management. IK carried out clinical fieldwork and supported the translation of the protocols. CP entered and cleaned data. SA coordinated the fieldwork and communicated with local authorities. CFRH coordinated the fieldwork, provided important intellectual content input for the study design.

Funding The study was supported by a project fund from the University Hospital Basel (VFWAWFPool-section medicine) and the "Freiwillige Akademische Gesellschaft Basel (FAG)."

Disclaimer The sponsors did not influence study design, or collection, analysis and interpretation of data, writing of the report or the decision to submit the report for publication.

Competing interests None declared.

Patient consent for publication Not required.

Ethics approval This study has been approved by the Ethical Committee of the Cantons Basel-Stadt and Basel-Land (University of Basel) Switzerland (No. 220/10), the Institutional Review Board of the Ifakara Health Institute in Tanzania (IH//RB/ No.20-2010) and by the Tanzanian National Institute for Medical Research (NIMR).

Provenance and peer review Not commissioned; externally peer reviewed.

Data availability statement Data are available on reasonable request. The original case report forms are stored at the Ifakara Health Institute in Bagamoyo Tanzania. The data and electronic files can be requested by the corresponding authors.

Open access This is an open access article distributed in accordance with the Creative Commons Attribution Non Commercial (CC BY-NC 4.0) license, which permits others to distribute, remix, adapt, build upon this work non-commercially, and license their derivative works on different terms, provided the original work is properly cited, appropriate credit is given, any changes made indicated, and the use is non-commercial. See: http://creativecommons.org/licenses/by-nc/4.0/.

ORCID iD

Michael Mayr http://orcid.org/0000-0002-1962-8186

\section{REFERENCES}

1 Hossain P, Kawar B, El Nahas M. Obesity and diabetes in the developing world--a growing challenge. $N$ Engl J Med 2007;356:213-5. 
2 WHO. Global report on diabetes, 2016. Available: https://www.who. int/diabetes/global-report/en/ [Accessed Feb.2018].

3 Atun R, Gale EAM. The challenge of diabetes in sub-Saharan Africa. Lancet Diabetes Endocrinol 2015;3:675-7.

4 Cho NH, Shaw JE, Karuranga S, et al. IDF diabetes atlas: global estimates of diabetes prevalence for 2017 and projections for 2045. Diabetes Res Clin Pract 2018;138:271-81.

5 Ahrén B, Corrigan CB. Prevalence of diabetes mellitus in northwestern Tanzania. Diabetologia 1984;26:333-6.

6 Aspray TJ, Mugusi F, Rashid S, et al. Rural and urban differences in diabetes prevalence in Tanzania: the role of obesity, physical inactivity and urban living. Trans $R$ Soc Trop Med Hyg 2000;94:637-44.

7 McLarty DG, Swai AB, Kitange HM, et al. Prevalence of diabetes and impaired glucose tolerance in rural Tanzania. Lancet 1989;1:871-5.

8 Hilawe $\mathrm{EH}$, Yatsuya $\mathrm{H}$, Kawaguchi L, et al. Differences by sex in the prevalence of diabetes mellitus, impaired fasting glycaemia and impaired glucose tolerance in sub-Saharan Africa: a systematic review and meta-analysis. Bull World Health Organ 2013;91:671-82.

9 Hall V, Thomsen RW, Henriksen O, et al. Diabetes in sub Saharan Africa 1999-2011: epidemiology and public health implications. A systematic review. BMC Public Health 2011;11:564.

10 WHO. Diabetes country profiles - United Republic of Tanzania, 2016 Available: https://www.who.int/diabetes/country-profiles/tza_en.pdf [Accessed Feb.2018].

11 Stanifer JW, Cleland CR, Makuka GJ, et al. Prevalence, risk factors, and complications of diabetes in the Kilimanjaro region: a population-based study from Tanzania. PLoS One 2016;11:e0164428.

12 Sacks DB. A1C versus glucose testing: a comparison. Diabetes Care 2011;34:518-23.

13 Florkowski C, HbA FC. HbA1c as a Diagnostic Test for Diabetes Mellitus - Reviewing the Evidence. Clin Biochem Rev 2013;34:75-83.

14 Hird TR, Pirie FJ, Esterhuizen TM, et al. Burden of diabetes and first evidence for the utility of $\mathrm{HbA} 1 \mathrm{c}$ for diagnosis and detection of diabetes in urban black South Africans: the Durban diabetes study. PLoS One 2016;11:e0161966.

15 Dagogo-Jack S, Assah F, Mbanya JC. Diabetes mellitus in developing countries and underserved communities, Chapter 3. In: ISBN:978-3-319-41559-8 Springer International Publishing, 2016[published Online First: 48].

16 Gallagher EJ, Le Roith D, Bloomgarden Z. Review of hemoglobin $A(1 c)$ in the management of diabetes. J Diabetes 2009;1:9-17.

17 Hodel NC, Hamad A, Praehauser C, et al. The epidemiology of chronic kidney disease and the association with non-communicable and communicable disorders in a population of sub-Saharan Africa. PLoS One 2018;13:e0205326.

18 Kassebaum NJ, Jasrasaria R, Naghavi M, et al. A systematic analysis of global anemia burden from 1990 to 2010 . Blood 2014;123:615-24.

19 Tanzania Population Census 2012. National Bureau of statistics Ministry of finance Dar ES Salaam. Available: https://www.nbs.go. tz/nbstz/index.php/english/statistics-by-subject/population-andhousing-census [Accessed Dec. 2017]

20 Levey AS, Stevens LA, Schmid CH, et al. A new equation to estimate glomerular filtration rate. Ann Intern Med 2009;150:604-12.

21 American Diabetes Association. Diagnosis and classification of diabetes mellitus. Diabetes Care 2010;33 Suppl 1:S62-9.

22 Classification and diagnosis of diabetes. The journal of clinical and applied research and education 2016;39:13-22.

$23 \mathrm{WHO}$. Use of glycated haemoglobin ( $\mathrm{HbA} 1 \mathrm{c})$ in the diagnosis of diabetes mellitus 2011, 2011. Available: https://www.who.int/ diabetes/publications/report-hba1c_2011.pdf [Accessed 2018].
24 ADA. Diabetes classification and diagnosis by fasting plasma glucose (Fpg). Available: https://www.diabetes.org/a1c/diagnosis [Accessed 2020].

$25 \mathrm{WHO}$. Haemoglobin concentrations for the diagnosis of anaemia and assessment of severity. vitamin and mineral nutrition information system. Geneva: World Health Organization. (WHO/NMH/ NHD/MNM/11.1), 2018. http://www.who.int/vmnis/indicators/ haemoglobin.pdf

26 R Core Team. R: a language and environment for statistical computing. $R$ foundation for statistical computing. Vienna, Austria, 2015. http://www.R-project.org/

27 Bullard KM, Cowie CC, Lessem SE, et al. Prevalence of Diagnosed Diabetes in Adults by Diabetes Type - United States, 2016. MMWR Morb Mortal Wkly Rep 2018;67:359-61.

28 Mathenge W, Foster A, Kuper H. Urbanization, ethnicity and cardiovascular risk in a population in transition in Nakuru, Kenya: a population-based survey. BMC Public Health 2010;10:569.

29 Mayega RW, Guwatudde D, Makumbi F, et al. Diabetes and prediabetes among persons aged 35 to 60 years in eastern Uganda: prevalence and associated factors. PLoS One 2013;8:e72554.

30 Mohamed SF, Mwangi M, Mutua MK, et al. Prevalence and factors associated with pre-diabetes and diabetes mellitus in Kenya: results from a national survey. BMC Public Health 2018;18:1215.

31 Bahendeka S, Wesonga R, Mutungi G, et al. Prevalence and correlates of diabetes mellitus in Uganda: a population-based national survey. Trop Med Int Health 2016;21:405-16.

32 Droumaguet C, Balkau B, Simon D, et al. Use of HbA1c in predicting progression to diabetes in French men and women: data from an epidemiological study on the insulin resistance syndrome (DESIR). Diabetes Care 2006;29:1619-25.

33 Mbanya JCN, Motala AA, Sobngwi E, et al. Diabetes in sub-Saharan Africa. Lancet 2010;375:2254-66.

34 Gill GV, Mbanya J-C, Ramaiya KL, et al. A sub-Saharan African perspective of diabetes. Diabetologia 2009;52:8-16.

35 Jeon CY, Murray MB. Diabetes mellitus increases the risk of active tuberculosis: a systematic review of 13 observational studies. PLoS Med 2008;5:e152.

36 Butler SO, Btaiche IF, Alaniz C. Relationship between hyperglycemia and infection in critically ill patients. Pharmacotherapy 2005;25:963-76.

37 Boillat-Blanco N, Ramaiya KL, Mganga M, et al. Transient hyperglycemia in patients with tuberculosis in Tanzania: implications for diabetes screening algorithms. J Infect Dis 2016;213:1163-72.

38 Hotez PJ, Kamath A. Neglected tropical diseases in sub-Saharan Africa: review of their prevalence, distribution, and disease burden. PLoS Negl Trop Dis 2009;3:e412.

39 WHO. World malaria report 2016. ISBN: 978924 151171. Available: https://www.who.int/malaria/publications/world-malaria-report2016/report/en/ [Accessed August 2017].

40 Nyirenda MJ. Non-Communicable diseases in sub-Saharan Africa: understanding the drivers of the epidemic to inform intervention strategies. Int Health 2016;8:157-8.

41 Bonora E, Tuomilehto J. The pros and cons of diagnosing diabetes with A1c. Diabetes Care 2011;34 Suppl 2:S184-90.

42 International Expert Committee. International expert Committee report on the role of the A1c assay in the diagnosis of diabetes. Diabetes Care 2009;32:1327-34.

43 Ford ES, Cowie CC, Li C, et al. Iron-Deficiency anemia, non-irondeficiency anemia and $\mathrm{HbA} 1 \mathrm{c}$ among adults in the US. J Diabetes 2011;3:67-73.

44 Ministry of Health, United Republic Tanzania, The World Diabetes Foundation: "The 2016 Dar es Salaam - Call to Action on diabetes and other non-communicable diseases", .2016. Available: http;// www.worlddiabetesfoundation.org/sites/default/files/NCD Stategic Plan 2016-2020.pdf[Accessed August 2017]. 